\title{
Low intra-tree variability in resistance to embolism in four Pinaceae species
}

\author{
Pauline S. Bouche ${ }^{1,2} \cdot$ Steven Jansen $^{1} \cdot$ Julia Cruz Sabalera $^{2} \cdot$ Hervé Cochard $^{3}$. \\ Régis Burlett $^{2} \cdot$ Sylvain Delzon ${ }^{2}$
}

Received: 1 October 2015 / Accepted: 11 April 2016/Published online: 2 May 2016

(C) INRA and Springer-Verlag France 2016

\begin{abstract}
- Key message Variability of embolism resistance within individual trees was assessed in four Pinaceae species by using a single method of measurement: the Cavitron. Contrary to what has been previously observed, our findings show a small variability in embolism resistance within and between organs. Indeed, we found (i) a lack of variability between branches within the crown, and (ii) that roots and trunks are either equally resistant or slightly more vulnerable to embolism than branches. This contradicts the vulnerability segmentation hypothesis proposed in the early 1990s. This paper also demonstrates that only few branches are necessary to determine the embolism resistance of a given tree.

- Context Embolism formation in xylem has an important impact on plant growth and survival. Since most studies on xylem embolism resistance focus on branches, it remains
\end{abstract}

Handling Editor: Erwin Dreyer

Contribution of the co-authors Julia Cruz Sabalera and Régis Burlett contributed to sampling material and data collection. Steven Jansen,

Hervé Cochard, and Sylvain Delzon supervised the study and revised the paper.

Electronic supplementary material The online version of this article (doi:10.1007/s13595-016-0553-6) contains supplementary material, which is available to authorized users.

Sylvain Delzon

sylvain.delzon@u-bordeaux.fr

1 Institute for Systematic Botany and Ecology, Ulm University, 89081 Ulm, Germany

2 BIOGECO, INRA, University of Bordeaux, 33610 Cestas, France

3 INRA, UMR 457 PIAF, Clermont University, 63100 Clermont-Ferrand, France questionable how the entire plant deals with embolism across organs.

- Aims In this study, we aimed to evaluate the variability of embolism resistance within a given organ and between different organs within a single tree.

- Methods Based on the Cavitron method, we estimated the intra-organ and the intra-plant variability of embolism resistance for four Pinaceae species. In addition, we compared pit anatomical characters for wood of all organs and species.

- Results We found no variability of embolism resistance for a given organ within a tree. At the tree level, trunks and roots were either equally or more vulnerable to embolism than branches. For all species, organs that showed a similar range of embolism resistance presented similar torus-aperture overlap values. However, the least negative $P_{50}$ value for roots of Pinus pinaster was associated with the lowest torus-aperture overlap value.

- Conclusion Our findings suggest that $P_{50}$ values are constrained within a particular organ and that intra-tree variation in embolism resistance is less substantial than previously reported. Moreover, our data do not support the vulnerability segmentation hypothesis which suggests that distal organs are more vulnerable to xylem embolism.

Keywords Conifers $\cdot$ Intra-plant variability $\cdot$ Embolism resistance - Vulnerability segmentation hypothesis .

Torus-margo pits

\section{Introduction}

Embolism resistance, estimated by the pressure inducing $50 \%$ loss of xylem hydraulic conductivity $\left(P_{50}\right)$, is strongly associated to drought stress resistance in both conifers (Brodribb and Cochard 2009; Brodribb et al. 2010) and angiosperms 
(Barigah et al. 2013; Urli et al. 2013). Although stems of conifers are on average more resistant to embolism than those of angiosperms, $P_{50}$ values vary widely within conifer taxa ( -2.1 to $-18.8 \mathrm{MPa}$; Maherali et al. 2004; Delzon et al. 2010; Pittermann et al. 2010; Larter et al. 2015). Bouche et al. (2014) showed that this tremendous variability of embolism resistance in the conifer taxa was strongly associated with the bordered pit structure in tracheids. In contrast, Lamy et al. (2014), in an intra-specific study on 513 genotypes of Pinus pinaster Aiton showed a very low variability of embolism resistance suggesting that this trait is highly constrained at the branch level within a species (Lamy et al. 2011). No significant difference in $P_{50}$ was found between populations of Pinus hartwegii Lindl. among an altitudinal gradient in Mexico (Sáenz-Romero et al. 2013) and at the intra-specific level between various conifer species (Anderegg 2014). However, embolism resistance in these studies was performed on branches only.

Within a single plant, comparison of vulnerability to embolism between different organs has been studied to understand drought resistance at the whole-plant level. How plant organs cope with embolism formation in a segmented or integrated way has an important impact on their growth and survival. Zimmermann (1983) initially proposed the hydraulic segmentation hypothesis suggesting that distal plant organs would be more subject to embolism events because of a decline in water potential from proximal to distal organs. Tyree and Ewers (1991) interpreted this hypothesis as the vulnerability segmentation hypothesis, suggesting that distal tissues are more vulnerable to embolism than proximal tissues to prevent embolism events in the main stem axis. While roots were found to be more resistant to embolism than stems in Populus and Juglans species (Cochard et al. 2002; Hukin et al. 2005), other intra-plant studies showed that roots and trunks were less resistant to embolism than branches (Sperry and Ikeda 1997; Martínez-Vilalta et al. 2002; Domec et al. 2006; Dalla-Salda et al. 2009; McCulloh et al. 2014).

Moreover, there is an important discrepancy between studies in $P_{50}$ values obtained for a given species and organ. For Pseudotsuga menziesii (Mirb.) Franco, for instance, reported $P_{50}$ varies from -2.45 to $-6.3 \mathrm{MPa}$ for branches, from -1.3 to $-4.7 \mathrm{MPa}$ for trunk segments, and from -1 to $-3.8 \mathrm{MPa}$ for roots (Sperry and Ikeda 1997; Martínez-Vilalta et al. 2002; Domec et al. 2006; Dalla-Salda et al. 2009; McCulloh et al. 2014). This discrepancy between studies could be due to the use of different sub-species that may differ in their habitat and vulnerability to embolism, or to the use of different hydraulic techniques that are applied to measure embolism resistance: air injection (Sperry and Ikeda 1997; Martínez-Vilalta et al. 2002; Domec et al. 2006; McCulloh et al. 2014), the centrifuge flow method (Dalla-Salda et al. 2009), dehydration (Domec et al. 2006), and ultrasonic acoustic emissions (McCulloh et al. 2014). In addition, various techniques have been used to compare organs of a single tree within a single study (McCulloh et al. 2014). Knowing that different hydraulic techniques can provide variable results (Cochard et al. 2013; Jansen et al. 2015), the variability of embolism resistance within a tree should ideally be measured with one single method.

Xylem anatomy between organs of a single tree can show considerable variation (Martínez-Vilalta et al. 2002; Domec et al. 2006; Schulte 2012; Schuldt et al. 2013). Because embolism resistance in conifers is related to the anatomy of bordered pits, $P_{50}$ is expected to vary with pit anatomical properties. While the anatomy of bordered pits has been widely studied in conifer branches, less is known about the variation of pit anatomy in trunks and roots (Hacke and Jansen 2009). Furthermore, even though it is common to use several samples from an individual tree to study the embolism resistance for a given species, it is important to consider both the intra-specific and intra-organ variability of $P_{50}$.

This paper investigates embolism resistance in branches, trunks, and roots of four Pinaceae species (P. menziesii, P. pinaster, Pinus sylvestris Herb., and Cedrus atlantica Endl.) based on the flow-centrifuge method (Cavitron). In addition, anatomical observations of bordered pits are carried out to determine if differences in $P_{50}$ are associated with the anatomy of torus-aperture overlap in bordered pits. Specific aims of this study are (1) to address the intra-organ variability of embolism resistance in P. pinaster and P. menziesii and (2) to test the vulnerability segmentation hypothesis for our four conifer species. Our results are important to encompass the ecophysiology of plants as most studies assessing the vulnerability to embolism are carried out on branches only.

\section{Materials and methods}

\subsection{Species studied}

We carried out this study on four common Pinaceae species from a temperate and Mediterranean climate that are widely represented in Europe and the USA: P. pinaster (Maritime pine), P. sylvestris (Scots pine), P. menziesii (Douglas fir) and $C$. atlantica (Atlas cedar). These four species are of particular economic importance for forestry because of their timber.

\subsection{Plant material and sampling}

Except for roots, sampling was carried on a single adult tree per species to minimize potential variation between tree genotypes. For all species, branches and trunk material were sampled following the same protocol.

Individuals of $P$. pinaster and $P$. menziesii were collected at the Institut National de la Recherche Agronomique of Pierroton (INRA, France; Table 1). Branch sampling was 
Table 1 Species studied, the age and height of the trees sampled, and the number of samples for each organ

\begin{tabular}{llllll}
\hline Species & Age & $\begin{array}{l}\text { Height } \\
(\mathrm{m})\end{array}$ & $\begin{array}{l}\text { Branch } \\
\text { samples }\end{array}$ & $\begin{array}{l}\text { Baguette } \\
\text { samples (trunk) }\end{array}$ & $\begin{array}{l}\text { Root } \\
\text { samples }\end{array}$ \\
\hline Pinus pinaster Aiton & 15 & 8 & 100 & 80 & 14 \\
Pseudotsuga menziesii (Mirb.) Franco & 45 & 12 & 80 & 60 & 9 \\
Pinus sylvestris Herb. & 75 & 15 & 6 & 24 & 3 \\
Cedrus atlantica (Endl.) G. Manetti ex Carrière & $>20$ & 10 & 6 & 4 & - \\
\hline
\end{tabular}

conducted before the dry season and early in the morning when plant water status is at its highest to minimize xylem embolism and needles were immediately removed after cutting. Branches were then wrapped up with humid paper and kept in plastic bags to avoid desiccation. Then, approximately 60-cm-long trunk segments (excluding nodes) were sampled and immediately transported to the GENOBOIS platform (INRA, Pierroton, France) where long sticks from the trunk (baguettes) were cut following a specific protocol. First, wood sections including the five outermost sapwood growth rings were cut with a chainsaw. Then, baguettes of $8 \times 8 \mathrm{~mm}^{2}$ (cross sectional area, corresponding at least to one growth ring) were re-cut with a double-bladed saw. Special attention was given to choosing the straightest growth rings to facilitate the cutting between latewood and earlywood tracheids. Baguettes were then conserved in cold water $\left(4^{\circ} \mathrm{C}\right)$ until measurements.

For $P$. pinaster and $P$. menziesii, 1-cm-diameter shade and light branches from the four azimuths of the five youngest whorls were sampled from the top to the bottom of the living crown (named W1 to W5; W1 being the youngest whorl; Fig. 1). On the same tree, five trunk segments were selected and the bark was marked to identify the height (H1 to H5; H1 being the highest segment; Fig. 1), with four azimuth locations for each segment. Trunk baguettes were cut from the four azimuths of each segment (Fig. 1). Root data, from intact adjacent individuals from the same monospecific and evenaged forest stands, were retrieved from Bouche et al. (2015) for $P$. pinaster and $P$. menziesii. Briefly, a powerful blower was used to expose the root system (radius of approximately $1.5 \mathrm{~m}$ and $60 \mathrm{~cm}$ deep from the base of the tree, Fig. 1) without causing mechanical tension or damage to the roots. Only roots of 50-cm length and less than 1-cm diameter were chosen. Individuals of $P$. sylvestris and $C$. atlantica were sampled at the INRA in Crouël (Clermont-Ferrand, France) following the same protocol except that only few samples per organ were collected (Table 1). Only the inter-organ variability was tested for the latter two species.

\subsection{Vulnerability curves}

Xylem embolism of branches, baguettes, and roots was assessed with the centrifuge flow technique (Cavitron; Cochard 2002; Cochard et al. 2005). Samples of $P$. pinaster and $P$. menziesii were measured at a high-throughput phenotyping platform (University of Bordeaux, France) and samples of $P$. sylvestris and $C$. atlantica at the CAVIDROME platform in Clermont-Ferrand (France).
Fig. 1 Intra-organ experimental design. Three to five samples for each azimuth and whorl were collected for branches. Three to five trunk baguettes were cut from each azimuth of five trunk segments. For roots, only the azimuth effect was taken into account and only one depth was considered $(<60$-cm deep; $n=2$ to 4 per azimuth)

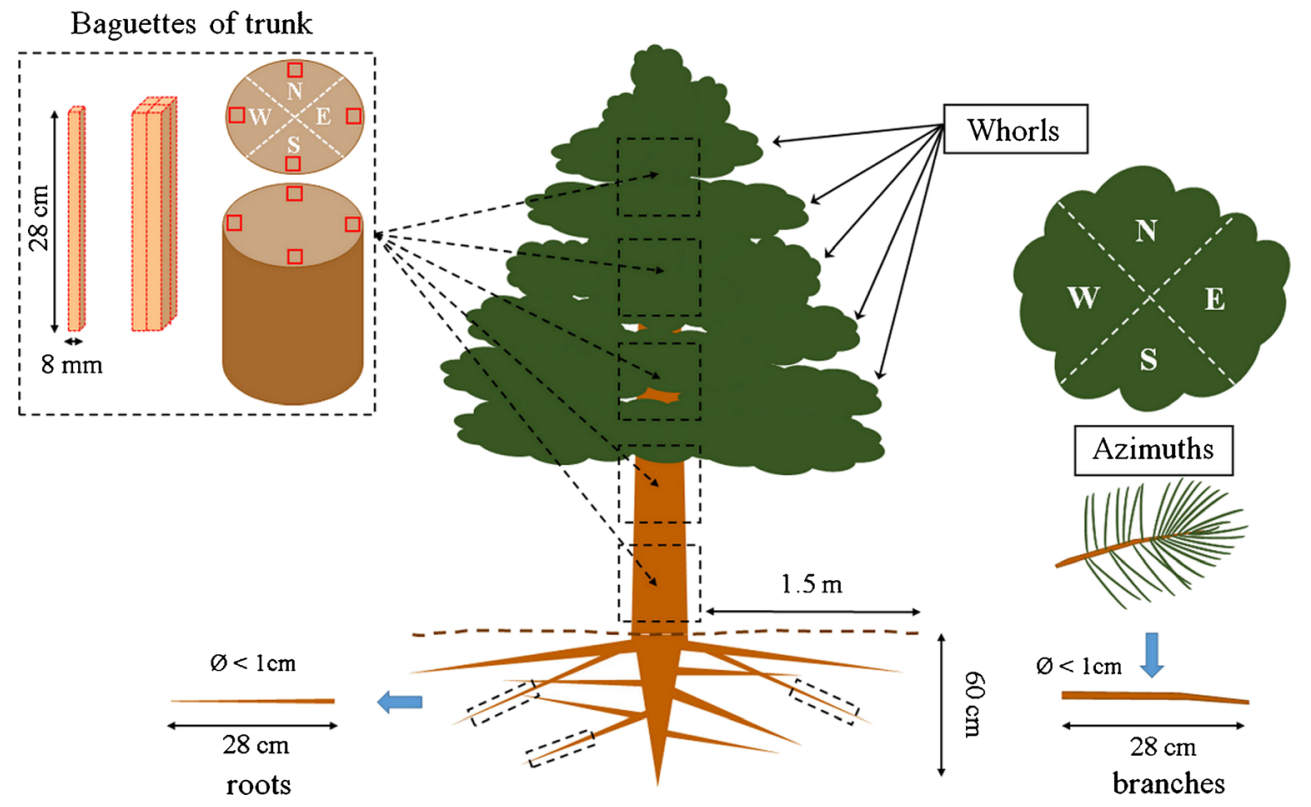


Prior to measurements, branches and baguettes were cut under water to a standard length of $27 \mathrm{~cm}$, and the bark was removed with a razor blade. Since torus-aperture sealing occurs in bordered pits of conifer xylem when these are subject to high pressure, removal of embolized tracheids is unlikely to be achieved by long vacuum infiltration, nor by flushing as commonly done for angiosperm wood segments (Delzon et al. 2010; Pivovaroff et al. unpublished data). Therefore, samples were not flushed before they were inserted in the cavitron sample holder. The samples were then infiltrated with a reference ionic solution of $10 \mathrm{mM} \mathrm{KCl}$ and $1 \mathrm{mM} \mathrm{CaCl}_{2}$ in deionized and ultrapure water, and centrifugal force was used to generate negative pressure into the xylem and induce embolism. Baguettes and branches were measured following the protocol of Dalla-Salda et al. (2009). For baguettes, open tracheids along the split longitudinal surfaces did not affect our vulnerability curve measurements because only the relative amount of water flowing through intact tracheids between both stem ends was used to obtain a vulnerability curve. Measurements on the actual specific hydraulic conductivity $\left(k_{\mathrm{s}}\right)$, however, might be affected by open tracheids in baguettes. The maximum hydraulic conductivity $\left(k_{\max }\right.$, $\left.\mathrm{m}^{2} \mathrm{MPa}^{-1} \mathrm{~s}^{-1}\right)$ was measured under low xylem pressures $(\psi$, close to $0 \mathrm{MPa}$ ). Then, the rotation speed of the centrifuge was gradually increased by 0.5 or $1 \mathrm{MPa}$ to lower the xylem pressure, and the corresponding hydraulic conductivity $\left(k_{\mathrm{i}}\right.$, $\mathrm{m}^{2} \mathrm{MPa}^{-1} \mathrm{~s}^{-1}$ ) was calculated. The percentage loss of conductivity (PLC) of branches and baguettes was determined at each pressure step following the equation:

Vulnerability curves were PLC $=100\left(1-\frac{k_{i}}{k_{\max }}\right)$ fitted using the equation of Pammenter and Vander Willigen (1998):

PLC $=\frac{100}{\left[1+\exp \left(\frac{s}{25} \times\left(\psi-p_{50}\right)\right)\right]}$

where $P_{50}(\mathrm{MPa})$ is the xylem pressure inducing $50 \%$ loss of conductivity, and $s\left(\% \mathrm{MPa}^{-1}\right)$ is the slope of the vulnerability curve at the inflection point.

Root data were retrieved from earlier cavitron measurements (Bouche et al. 2015) on embolism resistance for young roots ( $<1-\mathrm{cm}$ diameter) of $P$. pinaster and $P$. menziesii, including trees from the same even-aged forest at the INRA facility as the trees sampled in this paper.

\subsection{Anatomical observations}

Pit anatomical observations were carried out on samples used for hydraulic measurements. For each species, the SEM observations were limited to three samples per organ and a minimum of 50 measurements per trait. The TEM observations were limited to one sample per organ and species and a minimum of 20 measurements per trait evaluated. Samples that were closest to the average $P_{50}$ value were selected for anatomy.

\subsection{Scanning electron microscope}

Standard protocols were used to prepare branch, trunk, and root samples for SEM. Samples were cut with a fresh razor blade in order to have the radial tracheid walls exposed. After drying for $24 \mathrm{~h}$ in an oven at $60^{\circ} \mathrm{C}$, the samples were fixed on stubs, coated with gold using a sputter coater (108 Auto, Cressington, UK) for $40 \mathrm{~s}$ at $20 \mathrm{~mA}$, and observed under $5 \mathrm{kV}$ with a benchtop SEM (Phenom G2 pro, FEI, The Netherlands).

\subsection{Pit properties}

Based on previous studies (Domec et al. 2008; Delzon et al. 2010; Pittermann et al. 2010; Bouche et al. 2014), the torusaperture overlap $(O)$ appears to be tightly scaled to embolism resistance. Thus, SEM images of radial sections were used to measure the horizontal pit aperture diameter $\left(D_{\mathrm{PA}}\right)$ and horizontal torus diameter $\left(D_{\mathrm{TO}}\right)$ in order to determine the torusaperture overlap $\left(O=\left(D_{\mathrm{TO}}-D_{\mathrm{PA}}\right) / D_{\mathrm{TO}}\right)$. All anatomical data were based on earlywood tracheids, which are responsible for most of the hydraulic conductance (Domec and Gartner 2002).

\subsection{Statistical analyses}

Variation of embolism resistance $\left(P_{50}\right)$ between species; between organs (branch, trunk, and root); and within a single organ (whorls/height, azimuths) were assessed using a Wilcoxon-Mann-Whitney test. Data and statistical analyses were conducted using SAS software (version 9.4 SAS Institute, Cary, NC, USA). We also used coefficients of variation $(\mathrm{CVs})$ to compare the distribution of $P_{50}$ values within a given azimuth, whorl/height for branches and trunk baguettes of $P$. pinaster and P. menziesii.

\section{Results}

Vulnerability curves for all organs and species followed a sigmoidal shape as illustrated in Fig. S1. The average $P_{50}$ values for branches of $P$. menziesii, $P$. pinaster, and $P$. sylvestris were similar. $C$. atlantica was the most resistant species studied. Mean $P_{50}$ values of branches were -3.9 $\pm 0.31,-3.8 \pm 0.23$, and $-3.8 \pm 0.08 \mathrm{MPa}$ for $P$. menziesii, $P$. pinaster, and $P$. sylvestris, respectively, and -4.9 $\pm 0.2 \mathrm{MPa}$ for $C$. atlantica (Table 2). 
Table 2 Variation in bordered pit anatomy and embolism resistance between tracheids from branch, trunk, and root material of four conifer species

\begin{tabular}{|c|c|c|c|c|}
\hline & \multicolumn{2}{|c|}{ Anatomical traits } & \multicolumn{2}{|c|}{ Hydraulic traits } \\
\hline & $D_{\mathrm{PA}}$ & $D_{\text {Tо }}$ & $O$ & $P_{50}$ \\
\hline \multicolumn{5}{|c|}{ P. pinaster } \\
\hline Branch & $4.3 \pm 0.1 \mathbf{a}$ & $7.5 \pm 0.1 \mathbf{a}$ & $0.44 \pm 0.02 \mathbf{a}$ & $-3.76 \pm 0.23 \mathbf{a}$ \\
\hline Trunk & $6.0 \pm 0.3 \mathbf{b}$ & $10.2 \pm 0.3 \mathbf{b}$ & $0.42 \pm 0.05 \mathbf{a}$ & $-3.19 \pm 0.15 \mathbf{b}$ \\
\hline Root & $9.0 \pm 0.1 \mathrm{c}$ & $9.8 \pm 0.2 \mathbf{b}$ & $0.32 \pm 0.01 \mathbf{b}$ & $-2.58 \pm 0.13 \mathbf{c}$ \\
\hline \multicolumn{5}{|c|}{ P. menziesii } \\
\hline Branch & $4.1 \pm 0.09 \mathbf{a}$ & $6.9 \pm 0.1 \mathbf{a}$ & $0.40 \pm 0.01 \mathbf{a}$ & $-3.9 \pm 0.31 \mathbf{a}$ \\
\hline Trunk & $5.5 \pm 0.17 \mathbf{b}$ & $9.6 \pm 0.3 \mathbf{b}$ & $0.43 \pm 0.03 \mathbf{a}$ & $-3.37 \pm 0.22 \mathbf{b}$ \\
\hline Root & $4.3 \pm 0.12 \mathbf{b}$ & $9.0 \pm 0.5 \mathbf{b}$ & $0.43 \pm 0.01 \mathbf{a}$ & $-3.91 \pm 0.34 \mathbf{a}$ \\
\hline \multicolumn{5}{|c|}{ P. sylvestris } \\
\hline Branch & $4.1 \pm 0.1 \mathbf{a}$ & $6.9 \pm 0.1 \mathbf{a}$ & $0.40 \pm 0.03 \mathbf{a}$ & $-3.84 \pm 0.08 \mathbf{a}$ \\
\hline Trunk & $5.4 \pm 0.1 \mathbf{b}$ & $9.7 \pm 0.2 \mathbf{b}$ & $0.42 \pm 0.01 \mathbf{a}$ & $-3.20 \pm 0.25 \mathbf{b}$ \\
\hline Root & $5.8 \pm 0.1 \mathbf{b}$ & $10.3 \pm 0.2 \mathbf{b}$ & $0.43 \pm 0.03 \mathbf{a}$ & $-3.18 \pm 0.06 \mathbf{b}$ \\
\hline \multicolumn{5}{|c|}{ C. atlantica } \\
\hline Branch & $3.9 \pm 0.1 \mathbf{a}$ & $7.2 \pm 0.14 \mathbf{a}$ & $0.43 \pm 0.02 \mathbf{a}$ & $-4.92 \pm 0.17 \mathbf{a}$ \\
\hline Trunk & $5.1 \pm 0.1 \mathbf{b}$ & $8.9 \pm 0.18 \mathbf{b}$ & $0.44 \pm 0.02 \mathbf{a}$ & $-4.74 \pm 0.08 \mathbf{a}$ \\
\hline Root & - & - & - & - \\
\hline
\end{tabular}

Mean values $( \pm \mathrm{SE})$ of the horizontal pit aperture diameter $\left(D_{\mathrm{PA}} ; \mu \mathrm{m}\right)$, torus diameter $\left(D_{\mathrm{TO}} ; \mu \mathrm{m}\right)$, torus-aperture overlap $(O)$, and the water potential corresponding to $50 \%$ loss of hydraulic conductivity $\left(P_{50}, \mathrm{MPa}\right)$ are given. Bold letters $(\mathrm{a}, \mathrm{b}, \mathrm{c})$ indicate to what extent anatomical features are significantly different between organs within species. Anatomical data of roots of $P$. pinaster and $P$. menziesii were retrieved from Bouche et al. (2015)

\subsection{Intra-organ variability}

The intra-organ variability for embolism resistance $\left(P_{50}\right)$ was similar in both $P$. pinaster and $P$. menziesii (Table 3). No

Table 3 Effect of azimuth, whorl/height, and azimuth $\times$ whorl/height for embolism resistance of branches $\left(P_{50 \mathrm{Branch}}\right)$, trunks $\left(P_{50 \mathrm{Trunk}}\right)$, and roots $\left(P_{50 \text { Root }}\right)$ of $P$. pinaster and $P$. menziesii $(p$ value $<0.05)$, was assessed with a Wilcoxon-Mann-Whitney test

\begin{tabular}{|c|c|c|c|c|c|c|}
\hline \multirow[t]{2}{*}{ Variable } & \multicolumn{2}{|c|}{$P_{50 \text { Branch }}$} & \multicolumn{2}{|l|}{$P_{50 \text { Trunk }}$} & \multicolumn{2}{|l|}{$P_{50 \text { Root }}$} \\
\hline & $p$ value & $n$ & $p$ value & $n$ & $p$ value & $n$ \\
\hline \multicolumn{7}{|l|}{ P. pinaster } \\
\hline Azimuth & 0.0944 & 100 & 0.7048 & 80 & 0.8615 & \\
\hline Whorl/height & 0.2073 & 100 & 0.7158 & 80 & - & \\
\hline Azimuth $\times$ whorl/height & 0.5738 & 100 & 0.7708 & 80 & - & \\
\hline \multicolumn{7}{|l|}{ P. menziesii } \\
\hline Azimuth & 0.8946 & 80 & 0.0880 & 60 & 0.4595 & 9 \\
\hline Whorl/height & 0.2414 & 80 & 0.2646 & 60 & - & \\
\hline Azimuth $\times$ whorl $/$ height & 0.3663 & 80 & 0.0670 & 60 & - & \\
\hline
\end{tabular}

For roots, only the azimuth effect was taken into account (see experimental design, Fig. 1) significant effect of azimuths, whorl/height (Table 3, Fig. 2), and of the azimuths $\times$ whorl/height interaction was found for embolism resistance in branches and trunk baguettes (Table 3). For roots, only the azimuth effect was tested and was found to be insignificant (Table 3). In addition, for each organ, the $P_{50}$ values measured for a given azimuth, whorl or height showed a relatively small variability (average $\mathrm{CV}_{\text {branch }}=6.1 \pm 1.3 \%$ and $7.9 \pm 1.2 \% ; \mathrm{CV}_{\text {trunk }}=4.6 \pm 0.9 \%$, and $6.6 \pm 2.1 \%$ for P. pinaster and P. menziesii, respectively).

\subsection{Inter-organ variability}

Trunks were always significantly more vulnerable than branches, except for $C$. atlantica, for which $P_{50}$ values of branches and trunks were similar (Table 2, Fig. 3). Roots were more vulnerable than branches in the two Pinus species, and similar to branches in P. menziesii (Table 2, Fig. 3). However, the difference between roots and branches was highest in $P$. pinaster $\left(P_{50}=-3.7 \pm 0.23\right.$ and $-2.58 \pm 0.13 \mathrm{MPa}$ for branches and roots, respectively; Table 2, Fig. 3).

Dimensions of bordered pits $\left(D_{\mathrm{PA}}\right.$ and $\left.D_{\mathrm{TO}}\right)$ of the trunk and roots were significantly different from branches (Table 2) and no correlation was observed with $P_{50}$. In particular, roots and trunks tend to have a larger pit aperture diameter $\left(D_{\mathrm{PA}}\right)$ and torus diameter ( $D_{\mathrm{TO}}$, Table 3, Fig. 4). However, the torusaperture overlap $(O)$ remained unchanged in all species, except for $P$. pinaster, which showed a much lower value of $O$ in roots than in branches and trunks $(O=0.44,0.42$, and 0.32 , for branches, trunks, and roots, respectively; Table 2, Fig. 4).

\section{Discussion}

Our results show that vulnerability to embolism for branches of P. menziesii, P. pinaster, and P. sylvestris are similar, but slightly different than $C$. atlantica. The intra-organ investigation highlighted no variability of embolism resistance within a given organ in $P$. pinaster and $P$. menziesii. This suggests that $P_{50}$ might be constrained within an organ and indicates that the usual approach of studying a few samples per individual provides a valid approach to estimate embolism resistance for a given organ. However, this generalization might be restricted to conifers only as it has been shown that shade/light conditions can have a significant implication in angiosperm embolism resistance (Cochard et al. 1999; Barigah et al. 2006; Herbette et al. 2010).

Recent studies have challenged the vulnerability segmentation hypothesis, reporting large differences in the magnitude of embolism resistance between organs with branch being dramatically more resistant than trunk and root (Sperry and Ikeda 1997; Martínez-Vilalta et al. 2002; Domec et al. 2006; Vilagrosa et al. 2012; McCulloh et al. 2014). Yet, one of our major results regarding the inter-organ variability is that 
Fig. 2 Mean $P_{50}(50 \%$ loss of conductivity, $\mathrm{MPa}$ ) values of branches $(\mathbf{a}, \mathbf{b})$ and trunk baguettes (c, d) per azimuth (a, c) and whorl/height (W1-5 and H15; b, d) of two conifer species: P. pinaster and P. menziesii. Error bars show standard errors
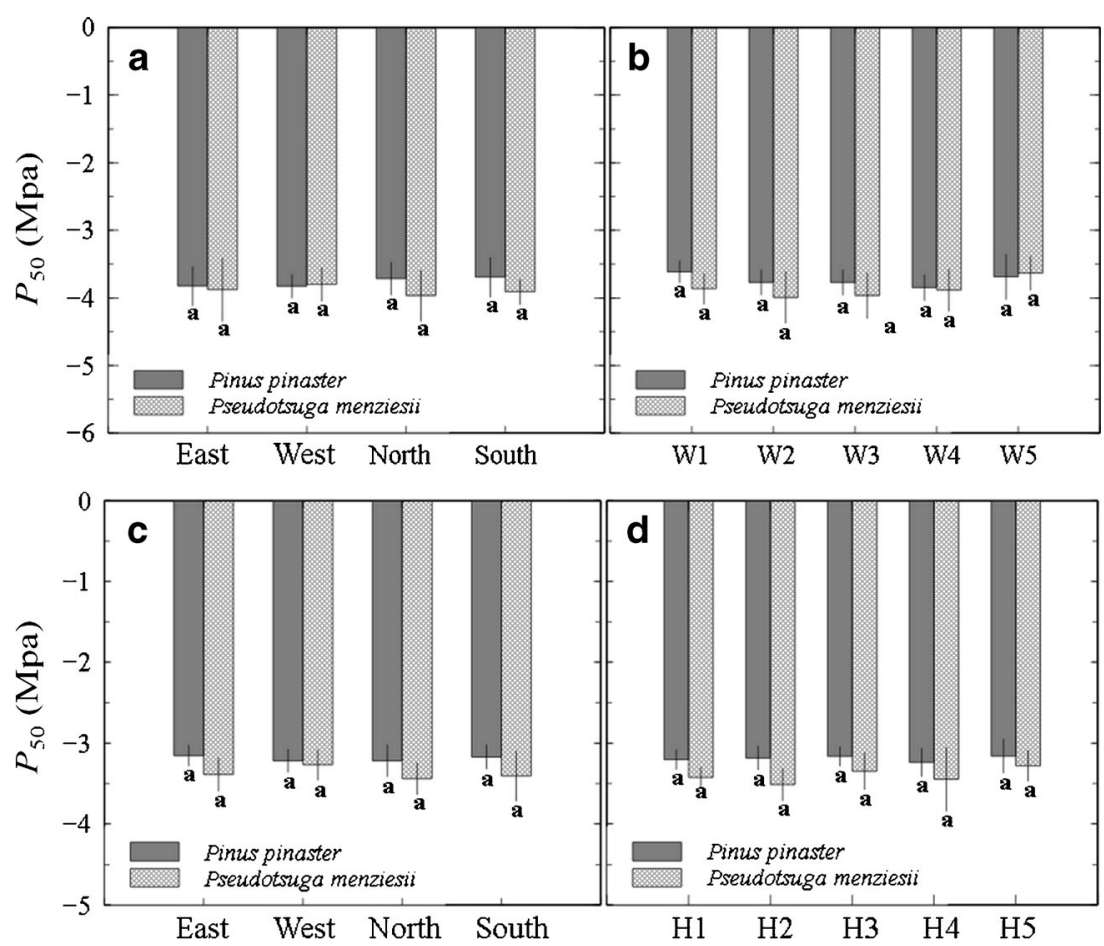

secondary xylem of the trunk and root is not as vulnerable to embolism as suggested previously. In particular, our results on $P$. menziesii demonstrate that when a single method is applied to measure $P_{50}$ for different organs, $P_{50}$ values show less variation between organs than previously reported for this species (Sperry and Ikeda 1997; Domec et al. 2006; McCulloh et al. 2014). This discrepancy could be explained by the application of different methods to determine embolism resistance between various organs within a tree. Although roots and trunks are either equally or more vulnerable to embolism than branch xylem for $P$. pinaster, $P$. sylvestris, and $C$. atlantica, the $P_{50}$ values of trunks and roots differ not more than $1 \mathrm{MPa}$ from those of branches. Moreover, Bouche et al. (2016) show that needles and stems of $P$. pinaster have a similar xylem embolism resistance based on x-ray computed tomography. These findings suggest that vulnerability to embolism varies only slightly at the whole-plant level, from the needles to the roots, and consequently do not support the vulnerability segmentation
Fig. 3 Vulnerability curves for branches (blue lines), trunks (green lines), and roots (red lines) of four conifer species (P. pinaster (a), P. menziesii (b), P. sylvestris (c), C. atlantica (d)) showing mean values of the PLC (loss of hydraulic conductivity in xylem, $\%$ ) as a function of xylem pressure $(\mathrm{MPa})$. The shaded bands represent the standard errors. $n_{\text {branch }}=81: 61: 6$, $n_{\text {trunk }}=65: 30: 24$, and $n_{\text {root }}=14: 9: 3$ for $P$. pinaster, P. menziesii, and P. sylvestris, respectively. For $C$. atlantica, only branches $(n=6)$ and trunk baguettes $(n=4)$ were measured
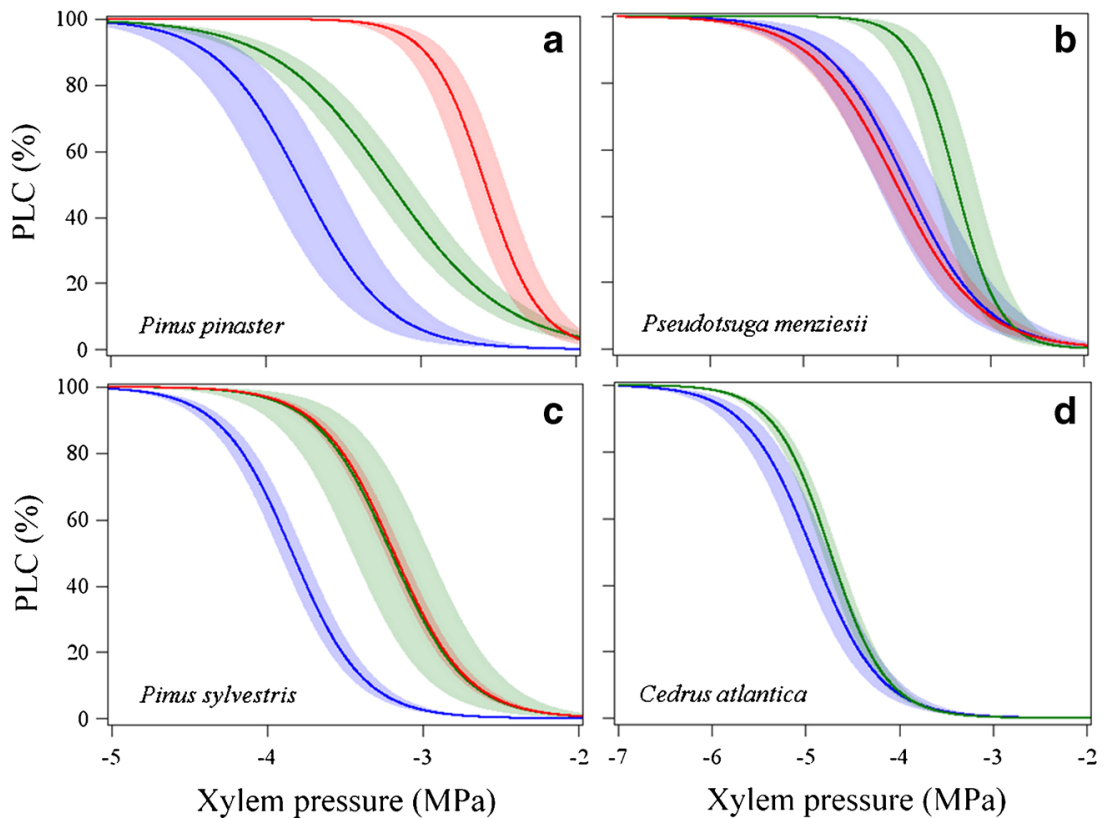
Fig. 4 Light microscopy images showing anatomical details of xylem tracheids in transverse sections of branches $(\mathbf{a}, \mathbf{b})$ and roots $(\mathbf{c}, \mathbf{d})$ from $P$. pinaster $(\mathbf{a}, \mathbf{c})$ and $P$. menziesii $(\mathbf{b}, \mathbf{d})$. Tracheid and torus-margo pits (arrows) are significantly different in size between branches and roots, especially in $P$. pinaster

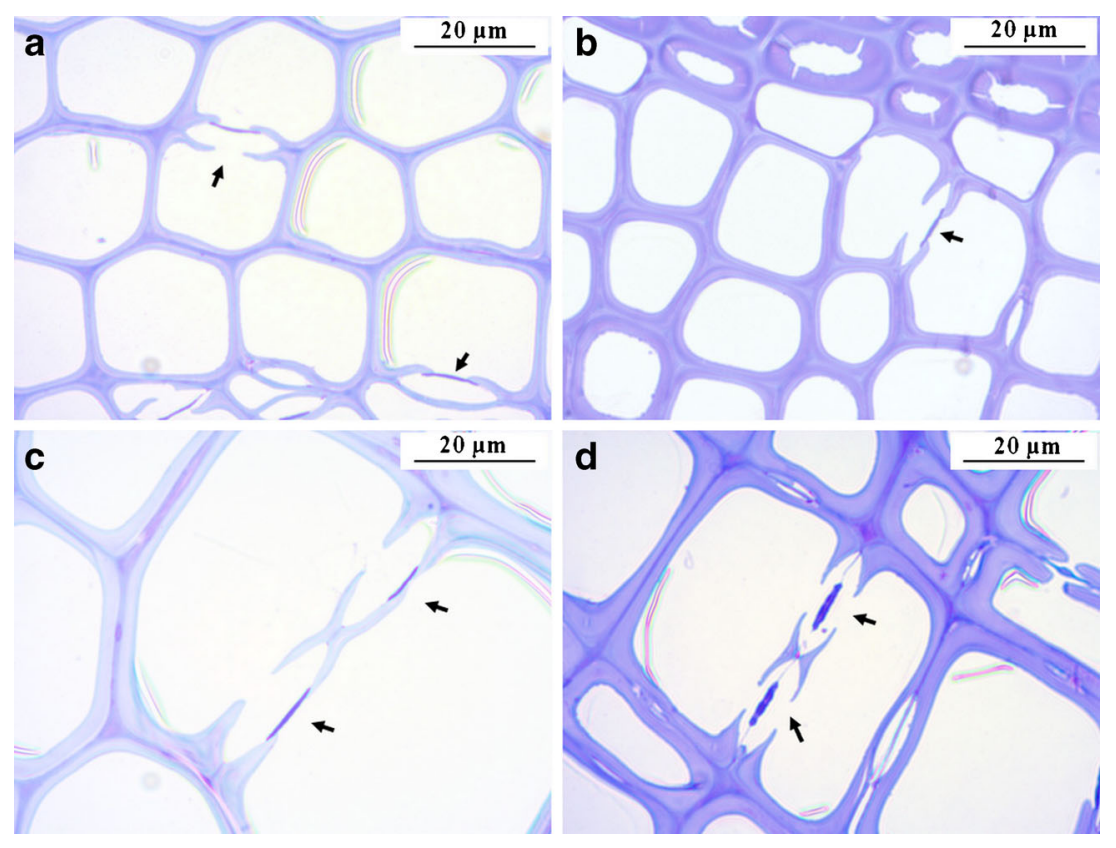

hypothesis (Tyree and Ewers 1991) and the "hydraulic fuse" hypothesis (Sperry et al. 1998).

In addition, our findings demonstrated that both roots and needles are slightly more or equally vulnerable to embolism than other organs. This challenges the view that the distal portions of the path (roots and/or distal stems or needles) are likely to experience xylem embolism at a daily and/or seasonal basis, which also questions refilling of embolized tracheids at night (Johnson et al. 2009, 2012). Under natural conditions, distal organs such as needles in $P$. pinaster may experience a seasonal minimum water potential of $-2 \mathrm{MPa}\left(\psi_{\min }\right.$, Delzon et al. 2004). According to Zimmermann (1983), the minimum seasonal water potential becomes less negative in a basipetal direction (i.e., from the leaves to the roots), which may decrease the risk of embolism from distal to proximal organs. Taken together, the limited variation in embolism resistance reported here suggests that a high amount of xylem embolism is unlikely under summer drought, either at the branch level or at the whole-plant level (Delzon and Cochard 2014). Thus, the idea that trees regulate stomatal conductance in such a way as to allow leaf water potential to approach the point at which excessive cavitation might occur (Novick et al. 2016) is very unlikely. Instead of sacrificing less costly organs to prevent the spread of embolism in the main axis (Zimmermann 1983; Tyree and Ewers 1991), Pine species can be suggested to keep a sufficiently high safety margin at the whole-plant level to avoid embolism. The tight link between $P_{50}$ of branches and the seasonal minimum of drought stress experienced by plants ( $\psi_{\text {min }}$, Choat et al. 2012) might be extrapolated to other organs and also at the whole-plant level. Organs operating at low safety margins could experience a larger amount of embolism than those with high safety margins. Therefore, measurements of the minimum seasonal water potential and the quantity of native embolism for different organs of a plant (especially trunk and roots) might be highly informative to encompass the hydraulic strategy of whole plants.

Our results on embolism resistance are well supported by anatomical observations. Previous studies stated that the torus-aperture overlap is the main parameter related to embolism resistance (Delzon et al. 2010; Pittermann et al. 2010; Bouche et al. 2014), and Bouche et al. (unpublished) showed that equally vulnerable needles and stems of $P$. pinaster have a similar value of torus-aperture overlap. In this study, values of torus-aperture overlap remain similar in all species and organs, except for $P$. pinaster, which has lower torus-aperture overlap in roots than in branches and trunks. Interestingly, the species that do not show variability in their torus-aperture overlap exhibit no or only low variability in $P_{50}$ between organs (from 0.2 to $0.6 \mathrm{MPa}$ difference). In contrast, a pronounced difference in $P_{50}$ between branches and roots (e.g., $>1 \mathrm{MPa}$ for $P$. pinaster), is in line with lower torus-aperture overlap in roots than in branches.

\section{Conclusion}

While embolism resistance of conifer branches has been widely studied at the inter-specific and intra-specific level, there is a real need to investigate root and trunk embolism resistance and safety margins on a broad taxonomic range of species to determine if assumptions made at the branch level are accurate for the whole plant. Our intra-organ comparison shows no variability of embolism resistance for a given organ, while our inter-organ analyses did not show a clear trend. In general, 
trunks seem to be slightly more vulnerable than branches, but roots can be either equally vulnerable or more vulnerable than branches. Thus, prospective work taking into account the inter- and intra-specific variability of embolism resistance for different organs might help us to fully understand the hydraulic pattern of plants. In addition, it would be interesting to test whether the relation between $P_{50}$ and torus overlap, which has mainly been studied for conifer branches (Bouche et al. 2014), also holds true for roots and trunks.

Acknowledgments The authors thank the Experimental Unit of Pierroton, UE 0570, INRA, 69 route d'Arcachon, 33612 CESTAS (France) for providing material and logistics. We also acknowledge the GENOBOIS platform (INRA, Pierroton, France) for preparation of trunk baguettes.

\section{Compliance with ethical standards}

Funding This work was supported by the program "Investments for the Future" (ANR-10-EQPX-16, XYLOFOREST) from the French National Agency for Research, and mobility grants from the Franco-German University (UFA).

\section{References}

Anderegg WRI (2014) Spatial and temporal variation in plant hydraulic traits and their relevance for climate change impacts on vegetation. New Phytol 205:1008-1014. doi:10.1111/nph.12907

Barigah TS, Ibrahim T, Bogard A, Faivre-Vuillin B, Lagneau LA, Montpied P, Dreyer E (2006) Irradiance induced plasticity in the hydraulic properties of saplings of different temperate broadleaved forest tree species. Tree Physiol 26:1505-1516

Barigah TS, Bonhomme M, Lopez D, Traore A, Douris M, Venisse JS, Cochard H, Badel E (2013) Modulation of bud survival in Populus nigra sprouts in response to water stress-induced embolism. Tree Physiol 33:261-274. doi:10.1093/aob/mct204

Bouche PS, Larter M, Domec J-C, Burlett R, Gasson P, Jansen S, Delzon S (2014) A broad survey of hydraulic and mechanical safety in the xylem of conifers. J Exp Bot 65:4419-4431. doi:10.1093/jxb/ eru218

Bouche PS, Jansen S, Cochard H, Burlett R, Capdeville G, Delzon S (2015) Embolism resistance of conifer roots can be accurately measured with the flow-centrifuge method. J Plant Hydraulics 2:002

Bouche PS, Delzon S, Badel E, Burlett R, Cochard H, Lavigne B, Mayr S, Zufferey V, Choat B, Brodribb TJ, Torres-Ruiz JM, CharraVaskou K, Li S, Morris H, Jansen S (2016) Are needles of Pinus pinaster more vulnerable to embolism than branches? New insights from x-ray computed tomography. Plant Cell Environ. doi:10.1111/ pce. 12680

Brodribb TJ, Cochard H (2009) Hydraulic failure defines the recovery and point of death in water-stressed conifers. Plant Physiol 149:575584. doi:10.1104/pp.108.129783

Brodribb TJ, Bowman DJMS, Nichols S, Delzon S, Burlett R (2010) Xylem function and growth rate interact to determine recovery rates after exposure to extreme water deficit. New Phytol 188:533-542. doi:10.1111/j.1469-8137.2010.03393.x

Choat B, Jansen S, Brodribb TJ et al (2012) Global convergence in the vulnerability of forests to drought. Nature 491:752-755. doi:10. 1038/nature 11688
Cochard H (2002) A technique for measuring xylem hydraulic conductance under high negative pressures. Plant Cell Environ 25:815-819

Cochard H, Lemoine D, Dreyer E (1999) The effects of acclimation to sunlight on the xylem vulnerability to embolism in Fagus sylvatica L. Plant Cell Environ 22:101-108

Cochard H, Coll L, Le Roux X, Ameglio T (2002) Unraveling the effects of plant hydraulics on stomatal closure during water stress in walnut. Plant Physiol 128:282-290. doi:10.1104/pp.010400

Cochard H, Damour G, Bodet C, Tharwat I, Poirier M, Ameglio T (2005) Evaluation of a new centrifuge technique for rapid generation of xylem vulnerability curves. Physiol Plant 124:410-418. doi:10. 1111/j.1399-3054.2005.00526.x

Cochard H, Badel E, Herbette S, Delzon S, Choat B, Jansen S (2013) Methods for measuring plant vulnerability to cavitation: a critical review. J Exp Bot 15:4779-4791. doi:10.1093/jxb/ert193

Dalla-Salda G, Martínez-Meier A, Cochard H, Rozenberg P (2009) Variation of wood density and hydraulic properties of Douglas-fir (Pseudotsuga menziesii (Mirb.) Franco) clones related to a heat and drought wave in France. For Ecol Manag 257:182-189. doi:10. 1016/j.foreco.2008.08.019

Delzon S, Sartore M, Burlett R, Dewar R, Loustau D. (2004) Hydraulic responses to height growth in maritime pine trees. Plant Cell Environ 27: 1077-1087. doi:10.1111/j.1365-3040.2004.01213.x

Delzon S, Douthe C, Sala A, Cochard H (2010) Mechanism of waterstress induced cavitation in conifers: bordered pit structure and function support the hypothesis of seal capillary-seeding. Plant Cell Environ 33:2101-2111. doi:10.1111/j.1365-3040.2010.02208.x

Delzon S, Cochard H. (2014) Recent advances in tree hydraulics highlight the ecological significance of the hydraulic safety margin. New Phytol 203:355-358. 10.1111/nph.12798

Domec JC, Gartner BL (2002) How do water transport and water storage differ in coniferous earlywood and latewood? J Exp Bot 53:2369 2379. doi:10.1093/jxb/erf100

Domec J-C, Lachenbruch B, Meinzer FC (2006) Bordered pit structure and function determine spatial patterns of air-seeding thresholds in xylem of Douglas-fir (Pseudotsuga menziesii; Pinaceae) trees. Am J Bot 93:1588-1600

Domec JC, Lachenbruch B, Meinzer FC, Woodruff DR, Warren JM, McCulloh KA (2008) Maximum height in a conifer is associated with conflicting requirements for xylem design. PNAS 105:12069 12074. doi:10.1073/pnas. 0710418105

Hacke UG, Jansen S (2009) Embolism resistance of three boreal conifer species varies with pit structure. New Phytol 182:675-686. doi:10. $1111 / j .1469-8137.2009 .02783 . x$

Herbette S, Wortemann R, Awad H, Huc R, Cochard H, Barigah TS (2010) Insights into xylem vulnerability to cavitation in Fagus sylvatica L.: phenotypic and environmental sources of variability. Tree Physiol 30:1448-1455. doi:10.1093/treephys/tpq079

Hukin D, Cochard H, Dreyer E, Le Thiec D, Bogeat-Triboulot MB (2005) Cavitation vulnerability in roots and shoots: does Populus euphratica Oliv., a poplar from arid areas of Central Asia, differ from other poplar species? J Exp Bot 56:2003-2010. doi:10.1093/ jxb/eri198

Jansen S, Schuldt B, Choat B (2015) Current controversies and challenges in applying plant hydraulic techniques. New Phytol 205: 961-964. doi:10.1111/nph.13229

Johnson DM, Woodruff DR, Mcculloh K, Meinzer FC (2009) Leaf hydraulic conductance, measured in situ, declines and recovers daily: leaf hydraulics, water potential and stomatal conductance in four temperate and three tropical tree species. Tree Physiol 29:879887. doi:10.1093/treephys/tpp031

Johnson DM, McCulloh KA, Woodruff DR, Meinzer FC (2012) Hydraulic safety margins and embolism reversal in stems and leaves: why are conifers and angiosperms so different? Plant Sci 195:48-53. doi:10.1016/j.plantsci.2012.06.010 
Lamy J-B, Bouffier L, Burlett R, Plomion C, Cochard H, Delzon S (2011) Uniform selection as a primary force reducing population genetic differentiation of cavitation resistance across a species range. PLoS ONE 6:e23476. doi:10.1371/journal.pone.0023476

Lamy J-B, Delzon S, Bouche P, Alia R, Vendramin GG, Cochard H, Plomion C (2014) Limited genetic variability and phenotypic plasticity detected for cavitation resistance in a Mediterranean pine. New Phytol 201:874-888. doi:10.1111/nph.12556

Larter M, Brodribb TJ, Pfautsch S, Burlett R, Cochard H, Delzon S (2015) Extreme aridity pushes trees to their physical limits. Plant Physiol 66:4643-4652. doi:10.1104/pp.15.00223

Maherali H, Pockman WT, Jackson RB (2004) Adaptive variation in the vulnerability of woody plants to xylem cavitation. Ecology, 85: 2184-2199. doi:10.1890/02-0538

Martínez-Vilalta J, Prat E, Oliveras I, Piñol J (2002) Xylem hydraulic properties of roots and stems of nine Mediterranean woody species. Oecology 133:19-29. doi:10.1007/s00442-002-1009-2

McCulloh KA, Johnson DM, Meinzer FC, Woodruff DR (2014) The dynamic pipeline: hydraulic capacitance and xylem hydraulic safety in four tall conifer species. Plant Cell Environ 37:1171-1183. doi: $10.1111 /$ pce. 12225

Novick KA, Miniat CF, Vose JM (2016) Drought limitations to leaf-level gas exchange: results from a model linking stomatal optimization and cohesion-tension theory. Plant Cell Environ 39:583-596. doi: 10.1111 pce. 12657

Pammenter N, Vander Willigen C (1998) A mathematical and statistical analysis of the curves illustrating vulnerability of xylem to cavitation. Tree Physiol 18:589-593

Pittermann J, Choat B, Jansen S, Stuart S, Lynn L, Dawson TE (2010) The relationships between xylem safety and hydraulic efficiency in the Cupressaceae: the evolution of pit membrane form and function. Plant Physiol 153:1919-1931. doi:10.1104/pp.110.158824

Sáenz-Romero C, Lamy J-B, Loya-Rebollar E, Plaza-Aguilar A, Burlett R, Lobit P, Delzon S (2013) Genetic variation of drought-induced cavitation resistance among Pinus hartwegii populations from an altitudinal gradient. Acta Physiol Plant 35:2905-2913. doi:10. 1007/s11738-013-1321-y

Schuldt B, Leuschner C, Brock N, Horna V (2013) Changes in wood density, wood anatomy and hydraulic properties of the xylem along the root-to-shoot flow path in tropical rainforest trees. Tree Physiol 33:161-174. doi:10.1093/treephys/tps122

Schulte PJ (2012) Vertical and radial profiles in tracheid characteristics along the trunk of Douglas-fir trees with implications for water transport. Trees 26:421-433. doi:10.1007/s00468-011-0603-5

Sperry JS, Ikeda T (1997) Xylem cavitation in roots and stems of Douglas-fir and white fir. Tree Physiol 17:275-280

Sperry JS, Adler FR, Campbell GS, Comstock JP (1998) Limitation of plant water use by rhizosphere and xylem conductance: results from a model. Plant Cell Environ 21:347-359

Tyree MT, Ewers F (1991) The hydraulic architecture of trees and other woody plants. New Phytol 119:345-360

Urli M, Porté AJ, Cochard H, Guengant Y, Burlett R, Delzon S (2013) Xylem embolism threshold for catastrophic hydraulic failure in angiosperm trees. Tree Physiol 33:672-683. doi:10.1093/treephys/ tpt030

Vilagrosa A, Chirino E, Peguero-Pina JJ, Barigah TS, Cochard H, GilPelegrin E (2012) Xylem cavitation and embolism in plants living in water-limited ecosystems. In Plant responses to drought stress. Springer Berlin, Heidelberg, pp 63-109

Zimmermann M (1983) Xylem structure and the ascent of sap. Springer, Berlin 